\title{
EXCISION WITH MIDLINE CLOSURE VERSUS MODIFIED BASCOM PROCEDURE IN TREATMENT OF SACROCOCYGEAL PILONIDAL SINUS
}

\author{
Ahmed Falih Noori", Nasseif Jassim Mohammed $^{\#}$ \& Zeki A AL-Faddag ${ }^{@}$ \\ ${ }^{*} \mathrm{MB}, \mathrm{ChB},{ }^{\#} \mathrm{CABMS}$, FICS, Dept.of Surgery, Al-Sadir Teaching Hospital. ${ }^{\circledR}$ CABS, FRCS, Professor of \\ General Surgery, Dept. of Surgery, Basrah College of Medicine, University of Basrah, IRAQ.
}

\begin{abstract}
Pilonidal sinus is a frequently encountered condition in young adults. It is commonly found in the mid-line skin that covers sacrum and coccyx. Sinus can be found elsewhere, sometimes between the fingers in hair dressers, and in the umbilicus. It is characterized by chronic inflammation in one or more sinuses in the mid-line of the natal cleft that contain hairs and debris. Pilonidal disease is a significant social and economic problem affecting predominantly young males in the second decade of life.

This study aimed to compare the results of excision and midline closure with those of lateral approach (Modified Bascom's procedure) in the treatment of sacro-coccygeal pilonidal sinus in regard to the duration of the procedure and wound complication.

This prospective randomized study was performed on 53 patients operated upon for a pilonidal sinus between June 2014 and December 2015 in Al-Sadir Teaching Hospital in Basrah. Patients were divided into two groups randomly. Group A (25) patients underwent modified Bascom procedure and group B (19) patients underwent excision and midline closure.

The modified Bascom technique showed a significantly short wound healing time ( $30 \pm 10$ days) compared to primary closure $(55 \pm 25$ days), $p<0.01$. The duration of this procedure was significantly longer( $50 \pm 15$ minute) in comparison with excision and midline closure $(30 \pm 15$ minutes) $p<0.01$.

No significant differences between the two groups regarding bleeding, wound infection, seroma formation and recurrence were recorded.

In conclusion, modified Bascom procedure is feasible, effective and applicable for all patients with pilonidal sinus. It is of particular advantages in the treatment of complex, recurrent and chronic non-healing pilonidal sinuses when wound healing remains an important dilemma in the surgical treatment.
\end{abstract}

\section{Introduction}

Pilonidal sinus is a frequently
encountered. These sinuses and cysts

elucidated $^{5}$. Initially considered an are commonly found in the mid-line skin that cover sacrum \& coccyx. Although usually found near the coccyx, the condition can also affect the navel, armpit or genital region, though these locations are much rarer ${ }^{1}$. Pilonidal disease is a significant social and economic problem, affecting predominantly young males in the second decade of life ${ }^{2}$. It is a common suffering among the military; it has been referred to as 'jeep disease, ${ }^{3}$. Incidence is reported at 26 per 100,000 population ${ }^{4}$. Pilonidal disease was first described by Mayo in 1833, but it took quite some time before etiology and pathogenesis were infection of subcutaneous ectodermal remnants present because of imperfect embryological development. Pilonidal sinus disease is now generally believed to be an acquired condition ${ }^{6,7}$.

Karydakis described the causative process extensively, explaining the three factors which are necessary to cause pilonidal disease; Invading loose hair, which could also originate from the back or neck, some force causing hair insertion, for example riding in a jeep, and the loss of barrier function of the skin in a deep and wet natal cleft with maceration and bacterial colonization. This barrier function is also lost in a surgical scar in 
this region ${ }^{5,7}$. Numerous techniques and modifications are in use aimed at these three factors in order to treat and prevent pilonidal disease, however, despite a recent Cochrane review by McCallum et al, a consensus for treatment of pilonidal disease has never been formed ${ }^{8-10}$. Furthermore, off-midline closing techniques demonstrated better results than midline closing techniques, however, data was limited in traditional excision of the cyst, leaving the wound open to heal by secondary intention, is still used frequently by surgeons worldwide. However, healing time is lengthy and recurrence rates are high $^{4,11,12}$. Less invasive procedures such as simple incision with curettage or excision with primary closure do lead to faster convalescence, but also result in a midline scar in a persistent deep natal cleft, potentially leading to high recurrence rates $^{7,13}$. In order to avoid median recurrences and flatten the natal cleft, surgeons have developed numerous procedures such as the Karydakis technique ${ }^{5,14,15}$, Bascom procedure ${ }^{16-18}$ and other asymmetrical closing techniques ${ }^{19}$ such as rhomboid excision with Limberg $^{20-23}$ or Dufourmentel flap closure $^{24}$, z-plasty ${ }^{25}$ or rotation flap ${ }^{26}$. In general, results of these asymmetrical closure and flap techniques seem better than results of open technique or primary midline closure techniques, although the surgical trauma is more extensive, and cosmetic results are not always optimal.

This study aimed to compare the results of excision and midline closure with those of lateral approach (Modified Bascom's procedure) in the treatment of sacrococcygeal pilonidal sinus in regard to the duration of the procedure, wound healing, post-operative bleeding, wound infection, seroma formation and recurrence.

\section{Patients and Methods}

Over 18 months, 53 patients with pilonidal sinus were admitted to the surgical unit of Al-Sadir Teaching Hospital in Basrah during the period between (June 2014-December 2015) (Table I). Forty patients presented with pain only and 13 patients presented with discharge and pain. No patient had a history of pilonidal abscess drainage and most of the patients have two pits except three of them have one pit.

Patients with chronic disease such as diabetes mellitus and ischemic heart disease, those on chronic use of steroid and those with BMI $>30$ were excluded from the study.

Nine patients were omitted from further follow-up, three cases related to modified Bascom procedure and six cases related excision and midline closure; therefore, they were also excluded from the study.

The remaining 44 patients divided into two groups randomly. Group A, 25 patients underwent modified Bascom procedure. And group B, 19 patients underwent excision and midline closure. All patients underwent elective operation for pilonidal sinus after an informed consent. Their age range from (18-40) (mean age was 29 years). Patients were admitted one day before the operation and received single dose of antibiotic in form of cefotaxime (500 mg) one hour before surgery. Under general ansthsea, the patients were positioned prone with the buttocks strapped apart. Probing was used to localize the extension of the tract, and methylene blue followed by elliptical incision so that all tissues between skin down to the sacral area was excised with all lateral tracts. Hemostasis was secured by cauterization. This was applied to 19 patients (group-B) who underwent wide local excision and midline closure by interrupted sutures.

Another 25 patients underwent lateral approach (Modified Bascom's procedure).

The patient lies prone and local infiltrative anesthesia is satisfactory. Three patients in group $\mathrm{A}$, the anesthesia changed from the local to general, two of them refuse local anesthesia, the other 
because of intractable pain. The buttocks are strapped apart. Each pit is excised with the pointed no.11 blade, removing a diamond-shaped piece of skin no larger than a rice grain, but to include the epithelialized portion of the pit which extends down for 2-3 $\mathrm{mm}$. An incision of 2-3 cm in length is then made approximately $2 \mathrm{~cm}$ from the midline. A probe introduced into a pit may act as a guide as to which side to make this lateral incision if there is no other evidence of previous lateral infection. The incision is positioned so that it is alongside the area of the cleft in which the puncti are present $^{27}$.

This incision serves three functions ${ }^{27}$ : First, it is used to enter the sinus system and curette out all hairs and infective granulation tissue. Second, through it the midline skin is released from its tethering to the post sacral fascia, and the depth of the natal cleft is reduced. Third, as the incision is left open, it relieves any tension on the subsequent closure of the pits.

The buttock strapping is then removed to relieve tension and each pit excised and closed with a 5/0 subcuticular nylon suture. The remaining steps described in the original Bascom procedure are omitted, in which a fibro-fatty flap is rotated under the midline skin. A wick soaked in iodine is simply tucked into the lateral wound so that it lies under the midline, and is removed after 48 hours. The duration of the procedure was calculated and started from incision until the closure of the wounds in both groups. A course of antibiotics is given, the pit closure sutures are removed at 1 week, and healing of the lateral wound is usually completed by 2 weeks.

All patients discharged in the next postoperative day with course of antibiotics in the form of Cefixim capsule (suprax) $400 \mathrm{mg}$ once daily, metronidazole $500 \mathrm{mg}$ three times daily and oral analgesia. The follow-up visit was 1 week after the surgery, then every two weeks for six months. No patient has bilateral sinus extension.

Data were analyzed using SPSS (Statistical Package for Social Science version 17).

\section{Results}

Between the two groups, no significant statistical difference in demographical data was found.

The mean duration of symptoms for all patients was 1.4 year before the operation. The primary outcome was wound healing. Other outcomes were procedure duration, recurrence and complications (e.g. bleeding, infection and seroma formation).

Table I: Patient's age

\begin{tabular}{|l|c|}
\hline Age of patients & Number \\
\hline$<\mathbf{2 0}$ years & 1 \\
\hline $\mathbf{2 0}-\mathbf{3 0}$ years & 42 \\
\hline$>\mathbf{3 0}$ years & 1 \\
\hline
\end{tabular}

Procedure time was significantly longer $A(50 \pm 15$ minute) versus( $30 \pm 15$ minute $)$ in in the modified Bascom procedure group group $\mathrm{B} p<0.01$ as shown in Table II.

Table II: Duration of procedure in the two groups

\begin{tabular}{|l|l|l|l|}
\hline Time in minutes & Group A & Group B & P value \\
\hline Duration of procedure & $50 \pm 15$ minute & $30 \pm 15$ minute & $<0.01$ \\
\hline
\end{tabular}

Patients underwent modified Bascom have faster wound healing ( $53 \pm 10$ days) than patients underwent excision and midline closure $(55 \pm 25$ days $)$, so there is significant difference, $\mathrm{P}$ value $<0.01$ as demonstrated in Table III.

Eight patients from 25 (32\%) in group A, and 10 patients from 19 (52.6\%) in group 
B developed postoperative wound infection, so there is no significant difference ( $\mathrm{P}$ value 0.03 ). Only one patient from group $\mathrm{B}$ developed bleeding during

excision and midline closure at time of surgery and so required suturing with $3 / 0$ absorbable suture (vicryle) and the bleeder stopped immediately (P value 0.26 ).

Table III: Complications in both groups

\begin{tabular}{|l|l|l|l|}
\hline & Group A & Group B & P value \\
\hline Wound healing & $53 \pm 10$ days & $55 \pm 25$ days & $<0.01$ \\
\hline Wound infection & $8(32 \%)$ & $10(52.6) \%$ & 0.03 \\
\hline Bleeding & $\mathbf{0 \%}$ & $1(5.2 \%)$ & 0.26 \\
\hline Recurrence & $2(8 \%)$ & $3(15.7 \%)$ & 0.22 \\
\hline
\end{tabular}

As Table III shows, only two (8\%) patient from group A underwent Modified Bascom procedure developed recurrence. And three (15.7\%) patients from 19 underwent excision and midline closure, so there is no significant difference $\mathrm{P}$ value (0.22). No patient from the two groups developed seroma.

\section{Discussion}

Pilonidal disease is an illness which appear in younger population (second and third decades) dominantly in male and especially in hairy persons ${ }^{27,28}$.

The outcome of the wound after surgery depend on the factors including, a closed humid environment and serosanguineous fluid collections.

In this study, most patients presented in the second decade of life, the age at which sex hormone is known to maximally affect pilo-sebaceous glands ${ }^{29}$.

Our data shows that procedure time is significantly longer in group A compared with group $B$ because the technique involved in modified Bascom included excision of each pit separately with preservation of the tissue between skin and sacral fascia, so it's longer than excision with midline closure. The patients had significant fast wound healing resulting in faster convalescence and return to work after surgery in group A patients, because in modified Bascom procedure excision only the pits and small lateral incision to extract the pits, so there is no extensive excision of the tissue which facilitate the fast wound healing compared with excision and midline closure.

In comparison with other similar study done in Guy's Hospital ${ }^{14}$, the duration of procedure for modified Bascom procedure was $49 \pm 15$ minutes and the time required for wound healing was $29 \pm 17$ days. No patient developed bleeding, so this result supports our study.

Bleeding occurred in one patient in group $\mathrm{B}$ and null in group $\mathrm{A}$. This bleeding occurred because of injury to veins in the surgical site, and this can be happen in any surgery.

More wound infections are observed after primary closure. The patients that developed wound infection in group A had poor wound care, three of them discontinued the postoperative treatment and wound care, the remaining five patients returned to work after 10 days following surgery.

The higher infection rate found in primary closure technique is probably realistic, the site of the wound in the midline (natal cleft) which is affected by movement, over sweating, poor hygiene and excessive pilosity. All these causes may participates in wound infection.

Furthermore, there is no significant difference in recurrence rate in the two patient groups.

In group $\mathrm{A}$, the complication may be incomplete resection of the tract, and in group $B$ hairs may enter in the wound from its lower edge, or might be hairs or debris invade the midline wound, however there is not enough time to observe the 
recurrence rate. All the patients that developed recurrence underwent excision and left the wound for secondary healing. In comparison with other similar study, our results shows that wound infection in patients underwent Modified Bascom procedure occurred in 8 from 40 patients (20\%), the recurrence of pilonidal sinus occurs in $4 / 40(10 \%)$, and only two patients developed seroma $2 / 40(5 \%)^{19}$ and this also supports our study.

Similar results were obtained in a study done on 141 patients underwent modified Bascom, no recurrence was observed and this supports this study ${ }^{22}$.

In conclusion, the ideal therapy for pilonidal sinus disease should be simple, have a low recurrence rate, require minimal wound care, and allow quick return to normal activity.

Earlier healing, shorter time off work and low recurrence rate are the main advantages of Modified Bascom's procedure (lateral approach) relative to excision with midline closure in pilonidal sinus surgery. So results showed that there were no major differences in the complications rates between the two techniques. We conclude that modified Bascom procedure is feasible, effective and applicable for all patients with pilonidal sinus. It is of particular advantages in the treatment of complex, recurrent and chronic non-healing pilonidal sinuses when wound healing remains an important dilemma in the surgical treatment however there is difficulty in management.

We favor and recommend the modified Bascom's natal cleft lift procedure in firstline treatment of all patients with pilonidal sinus and as a second line treatment for recurrent pilonidal sinus. It is safe, simple easily performed operation with few complications and minimal morbidity, although, infection remains a main problem in primary closure techniques. This could be one of the reasons why there is still no uniformity about the best treatment for pilonidal disease.

\footnotetext{
References

1. Rao, Amrith; Sharma, Mohit; Thyveetil, Mabel; Karim, Omer (December 2006). "Penis: An Unusual Site for Pilonidal Sinus". International Urology and Nephrology 38 (3-4): 607-608.

2. Klass, Alan (November 1, 1956). "The So-Called Pilo-Nidal Sinus". Canadian Medical Association Journal 75 (9): $737-742$. PMC 1823328. PMID 13364825. Retrieved February 8, 2013

3. Sondenaa K, Nesvik I, Anderson E, Natas O, Soreide J A. Patient characteristics and symptoms in chronic pilonidal sinus disease. Int J Colorectal Dis. 1995;10:39-42. [PubMed]

4. Sondenaa K, Andersen E, Nesvik I, et al: Patient characteristics and symptoms in chronic pilonidal sinus disease. Int J Colorectal Dis 1995;10(1):39-42.

5. Karydakis GE: Easy and successful treatment of pilonidal sinus after explanation of its causative process. Aust N Z J Surg 1992 May;62(5):385-389.

6. Patel MR, Bassini L, Nashad R, et al: Barber’s interdigital pilonidalsinus of the hand: a foreign body hair granuloma. J Hand Surg [Am] 1990 Jul;15(4):652655.

7. da Silva JH: Pilonidal cyst: cause and treatment. Dis Colon Rectum 2000 Aug:43(8):1146-1156.

8. Lund JN, Leveson SH: Fibrin glue in the treatment of pilonidal sinus: results of a pilot study. Dis Colon Rectum 2005 May; 48(5):1094-1096.

9. McCallum I, King PM, Bruce J: Healing by primary versus secondary intention after surgical treatment for pilonidal sinus. Cochrane Database Syst Rev 2007 Oct 17;(4):CD006213.

10. Dogru O, Camci C, Aygen E, et al: Pilonidal sinus treated with crystallized phenol: an eight-year experience. Dis Colon Rectum 2004 Nov;47(11):19341938.

11. al-Hassan HK, Francis IM, Neglén P: Primary closure or secondary granulation after excision of pilonidal sinus? Acta Chir Scand 1990 Oct;156(10):695699.

12. Morell V, Charlton BL, Deshmukh N: Surgical treatment of pilonidal disease: comparison of three different methods in fifty-nine cases. Mil Med 1991 Mar;156(3):144-146

13. Dalenback J: Prospective follow-up after ambulatory plain midline excision of pilonidal sinus and primary suture under local anaesthesia- efficient, sufficient, and persistent. Colorectal Dis 2006 Jan;8(1):73-74.

14. Morden P, Drongowski RA, Geiger JD, et al: Comparison of arydakis versus midline excision for treatment of pilonidal sinus disease. Pediatr Surg Int 2005 Oct;21(10):793-796.

15. Kitchen PR: Pilonidal sinus: experience with the Karydakis flap. Br J Surg 1996 Oct;83(10):1452-1455.

16. Bascom J, Bascom T: Failed pilonidal surgery: new paradigm and new operation leading to cures. Arch Surg 2002 Oct;137(10):1146- 1150

17. Senapati A, Cripps NP, Thompson MR: Bascom's operation in the day-surgical management of symptomatic pilonidal sinus.Br J Surg 2000 Aug;87(8):1067-1070.
Ans

18. Branagan G, Thompson MR, Senapati A: Cleft closure for the treatment of unhealed perineal sinus. Colorectal Dis 2006 May;8(4):314-317.

19. Mentes O, Bagci M, Bilgin T, et al: Management of pilonidal sinus disease with oblique excision and primary closure: results of 493 patients. Dis Colon Rectum 2006 Jan;49(1):104-108.

20. Cihan A, Ucan BH, Comert M, et al: Superiority of asymmetric modified Limberg flap for surgical treatment of pilonidal disease. Dis Colon Rectum 2006 Feb;49(2):244-249.

21. Akca T, Colak T, Ustunsoy B, et al: Randomized clinical trial comparing primary closure with the Limberg flap in the treatment of primary sacrococcygeal pilonidal disease. Br J Surg 2005 Sep;92(9):1081- 1084

22. Katsoulis IE, Hibberts F, Carapeti EA: Outcome of treatment of primary and recurrent pilonidal sinuses with the Limberg flap. Surgeon 2006 Feb;4(1):7-10, 62.

23. Ertan T, Koc M, Gocmen E, et al: Does technique alter quality of life after pilonidal sinus surgery? Am J Surg 2005 Sep;190(3):388-392.

24. Dufourmentel C, Mouly R, Baruch J, et al: Sacrococcygeal cysts and fistulas. Pathogenic and therapeutic discussion. Ann Chir Plast 1966 Sep;11(3):181186.

25. Monro RS, McDermott FT: The elimination of causal factors in pilonidal sinus treated by z-plasty. Br J Surg 1965 Mar;52:177-181.

26. Cherry JK: Primary closure of pilonidal sinus. Surg Gynecol Obstet 1968 Jun;126(6):1263-1269.

27. Rukavina B; Omergic H., Radical Treatment of pilonidal Sinus, Acta chir. Logusl, (cited from The Medline, abstract) 1989;36:287-93

28. Zimmer E.Z and Bronshtein M.Early Sonographic Findings Suggestive of Human fetal Tail, Prenatal Diag., 1996;16:360-62.

29. Alien- Mersh T.G. pilonidai sinus finding the right track for treatment, Br. L surg.1990;77:123-32.
} 